\title{
В.В. Пшеничников
}

\section{ПОКУПАТЕЛЬНАЯ СПОСОБНОСТЬ РУБЛЯ: ПРОБЛЕМЫ РЕГИОНАЛЬНОЙ ДИФФЕРЕНЦИАЦИИ И ПУТИ ИХ РЕШЕНИЯ}

\author{
V.V. Pshenichnikov \\ THE PURCHASING POWER OF THE RUBLE: \\ PROBLEMS OF REGIONAL DIFFERENTIATION \\ AND THE WAYS OF THEIR SOLUTION
}

\begin{abstract}
Изучена проблема региональной дифференциации уровня цен и покупательной способности денег в регионах России. Рассмотрена трактовка ценовой стабильности как цели денежно-кредитной политики. Исследована проблема определения покупательной способности современных денег. Обоснована взаимосвязь между покупательной способностью современных денег и уровнем заработной платы. Изучен опыт Немецкого федерального банка в части институциональных процедур реализации денежно-кредитной политики на региональном уровне. Рассмотрены возможности использования критериев конвергенции Европейского Сообщества в практике выравнивания уровня социально-экономического развития регионов России. В условиях региональной дифференциации уровня цен и покупательной способности российского рубля выйти на новый уровень гармонизации денежно-кредитной и бюджетной политики можно за счет как институциональных преобразований, так и внедрения целевых ориентиров, направленных на выравнивание уровней социально-экономического развития регионов России. Предложено расширить полномочия территориальных учреждений Банка России и использовать адаптированные к российским условиям ориентиры согласования денежно-кредитной и бюджетной политики. В качестве целевых ориентиров развития экономики регионов можно принять первоначально видоизмененные критерии конвергенции ЕС. Предлагается использовать для начала следующие три ориентира. Первый ориентир - показатель ценовой стабильности. Его можно оценивать по среднему уровню инфляции соответствующего региона за последние 12 месяцев, который сравнивается с показателями трех-пяти регионов, имевших самые низкие уровни инфляции. Второй ориентир - ограничение чрезмерного дефицита региональных бюджетов. Ограничение целесообразно устанавливать в процентах от внутреннего регионального продукта. Третий ориентир - соблюдение долгосрочных процентных ставок на определенном уровне, который складывается в тех же трех-пяти регионах страны, где фиксировался минимальный уровень инфляции. Нынешние проблемы стран зоны евро не могут дискредитировать эффективность критериев конвергенции, на которые мы здесь опираемся, поскольку предусмотренные изначально экономические рычаги воздействия за их нарушение нивелированы в итоге политическими решениями.

ДЕНЬГИ; ДЕНЕЖНО-КРЕДИТНАЯ ПОЛИТИКА; ИНДЕКС ЦЕН; ИНФЛЯЦИЯ; МАСШТАБ ЦЕН; ПОКУПАТЕЛЬНАЯ СПОСОБНОСТЬ ДЕНЕГ.

The article studies the problem of regional differentiation of the price level and the purchasing power of money in Russian regions. We have considered the interpretations of price stability as a goal of monetary policy and investigated the problem how to determine the purchasing power of modern money. The relationship between the purchasing power of modern money and wages is proved. We have studied the experience of the German Federal Bank in the sphere of institutional procedures to implement monetary policy at the regional level. The possibilities to use the convergence criteria of the European Community in the practice of equalizing the socio-economic development of Russian regions are studied. In terms of regional differentiation of the price level and the purchasing power of the Russian rouble, it is possible to reach a new level of the harmonization of monetary and fiscal policy using institutional transformations and the targets aimed at equalizing the levels of the socio-economic development of Russian regions. We offer to expand the powers of the territorial institutions of the Bank of Russia and use the guidelines for the harmonization of monetary and fiscal policies adapted to Russian conditions. The initially modified convergence criteria of the EU should be used as the targets of the economic development of regions. We propose to use the following three landmarks. The first landmark could be an indicator of price stability. It should be measured by the average inflation rate of the corresponding region in the last 12 months, which is equal to the performance of three or five regions having the lowest levels of
\end{abstract}


inflation. The second landmark could be the limitation of the excessive deficit of regional budgets. The limitation should be established as the percentage of the domestic regional product. The third landmark should be adherence to long-term interest rates at a certain level, which is formed in the same three or five regions of the country with a minimum level of inflation. We are sure that the current problems of Eurozone countries cannot discredit the effectiveness of the convergence criteria, because the initially envisaged economic leverage for their violation were ironed out as a result of political decisions.

MONEY; MONETARY POLICY; PRICE INDEX; INFLATION; THE SCALE OF PRICES; THE PURCHASING POWER OF MONEY

Введение. Ключевой целью проводимой Центральным банком Российской Федерации денежно-кредитной политики в последние годы было и остается таргетирование инфляции. При этом Основные направления денежнокредитной политики, разрабатываемые Банком России, прежде всего, исходят из прогнозов изменения мировых цен на нефть, в пределах колебания которых рассматриваются варианты динамики ключевых макроэкономических показателей российской экономики, в том числе ее денежно-кредитной сферы. Переход Банка России к принципу свободного образования валютного курса рубля усилили его волатильность, что не замедлило отразиться на темпах инфляции. Ориентируясь на данное обстоятельство, имеет смысл обратить внимание на степень достижимости Банком России ценовой стабильности.

Одной из актуальных проблем денежнокредитного регулирования экономики современной России видится широкий разброс в уровнях социально-экономического развития отдельных регионов страны. Различия в развитии региональных экономик оказывают негативное влияние на эффективность проводимой Банком России единой государственной денежно-кредитной политики в силу того, что вектор действий монетарных властей России вписывается в развитие одних регионов и вступает в противоречие с направлениями развития других. Таким образом, в масштабах экономики страны в целом успехи развития одних регионов поглощаются проблемами в развитии других. Усиление данного рода противоречий можно наблюдать и по другим составляющим финансовой политики, в частности при составлении и исполнении региональных и местных бюджетов. В этой связи мы попытаемся акцентировать внимание, с одной стороны, на актуализации институциональных преобразований органов денежнокредитного регулирования, с другой - на внедрении критериев гармонизации денежно-кредитной и бюджетной политики региональных властей.

\section{Методика исследования.}

1. Трактовка ценовой стабильности в качестве цели денежно-кредитной политики. Будучи составной частью общегосударственной экономической политики, денежно-кредитная политика должна быть «вписана» в общую стратегию развития национальной экономики, в частности, в ее финансовый сектор. Наиболее проблематичным здесь видится сочетаемость основных направлений денежнокредитной политики с промышленной, инвестиционной, бюджетной, налоговой и другими составляющими общегосударственной экономической политики. Учитывая наличие различных толкований термина «денежнокредитная политика», мы будем опираться на достаточно устоявшиеся представления о двух ее составляющих - денежной политике и кредитной политике, которые, в свою очередь, также имеют по две разновидности в зависимости от полагаемой цели (см. схему).

Согласно сложившимся суждениям большинства исследователей, денежная политика представляет собой совокупность мероприятий, направленных на изменение объема денежной массы, находящейся в обращении, и других показателей денежного рынка. При этом политика «дешевых денег» направлена на расширение предложения денег, а политика «дорогих денег», наоборот, на сокращение спроса на деньги. Кредитная политика представляет собой совокупность мероприятий, направленных на изменение объема кредитов, уровня процентных ставок и других показателей рынка ссудных капиталов. Соответственно кредитная экспансия нацелена на расширение объемов кредитования, в том числе за счет снижения процентных ставок, тогда как кредитная рестрикция имеет противоположную направленность. 


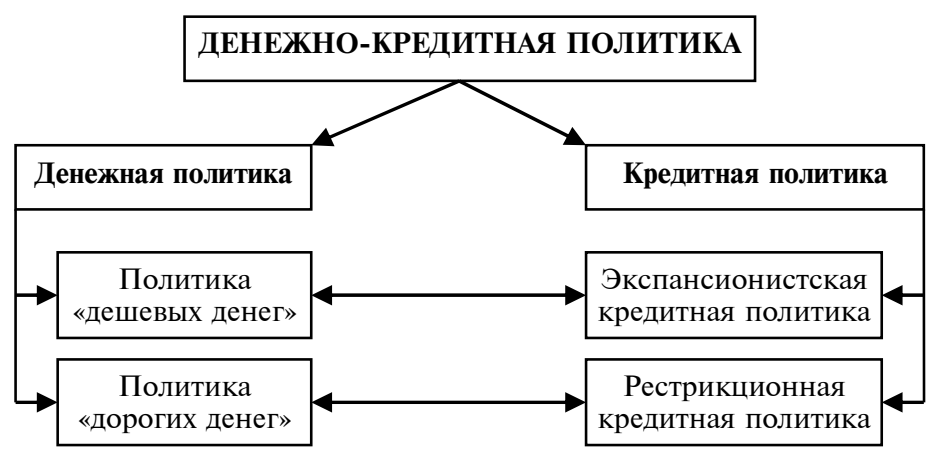

Составные части денежно-кредитной политики

Т а блица 1

Индексы потребительских цен по федеральным округам Российской Федерации в 2010-2013 гг.

\begin{tabular}{|l|c|c|c|c|}
\hline \multirow{2}{*}{\multicolumn{1}{|c|}{ Федеральный округ }} & \multicolumn{4}{|c|}{ Индекс цен, \% } \\
\cline { 2 - 5 } & 2010 & 2011 & 2012 & 2013 \\
\hline Российская Федерация & 108,8 & 106,1 & 106,6 & 106,5 \\
\hline Центральный & 108,9 & 106,0 & 106,9 & 106,7 \\
Северо-Западный & 109,2 & 105,8 & 106,1 & 106,6 \\
Южный & 109,0 & 106,1 & 106,6 & 106,6 \\
Северо-Кавказский & 110,6 & 105,2 & 106,6 & 106,1 \\
Приволжский & 109,3 & 106,2 & 106,4 & 106,3 \\
Уральский & 109,8 & 106,4 & 106,4 & 106,2 \\
Сибирский & 107,9 & 106,3 & 106,7 & 106,1 \\
Дальневосточный & 107,7 & 106,8 & 105,9 & 106,6 \\
\hline
\end{tabular}

П р и м е ч а н и . По состоянию на декабрь - к декабрю предыдущего года.

Понятие ценовой стабильности (price stability) как ключевой цели современной денежно-кредитной политики введено в оборот одним из прежних руководителей ФРС США А. Гринспэном в 1989 г. [8]. На практике под ценовой стабильностью понимают небольшое положительное значение прироста индекса цен до $3,5 \%$ в год в течение длительного периода времени. В разрезе денежных факторов порождения инфляции это тесным образом перекликается с известным монетарным правилом Милтона Фридмена, который допускал ежегодный темп прироста денежной массы в обращении в пределах 3$5 \%$. Такая инфляция не только не наносит вреда экономике, но даже, наоборот, стимулирует ее к дальнейшему росту.

Обеспечение ценовой стабильности есть не что иное, как поддержание устойчивости покупательной способности национальной валюты. Принято рассматривать два вида устойчивости покупательной способности национальной валюты - внешнюю и внутреннюю. Внешняя устойчивость определяется стоимостью валюты на международном рынке, внутренняя - соответственно на внутреннем рынке страны-эмитента. Очевидно, что, не обладая внутренней устойчивостью, ни одна национальная валюта не будет пользоваться успехом за пределами своей страны [12].

2. Проблема определения покупательной способности современных денег. Новой проблемой регулирования современной денежно-кредитной сферы стало появление электронных денег, что в глобальном масштабе породило процесс дематериализации носителей эталонной стоимости. В этой связи 
цель борьбы с инфляцией будет сводиться к поддержанию покупательной способности виртуальных денег, эмитенты которых могут функционировать и вне банковского сектора.

Процесс появления и распространения электронных денег сопоставим по своей значимости с заменой полноценных денег, которые изготавливались из благородных металлов, знаками стоимости, изготовленными из бумаги. В каждом из этих случаев мы сталкиваемся с замещением одного вещественного носителя эталонной стоимости другим, обладающим качественно новыми свойствами и позволяющим при этом экономить издержки обращения. Вместе с тем возникает необходимость в определении масштаба цен новых видов денег.

При обращении полноценных денег масштаб цен устанавливался в законодательном порядке как весовое содержание благородного металла (чаще всего золота) в денежной единице. Эта величина служила эталоном при определении товарных цен. Например, после Второй мировой войны масштаб цен на протяжении почти 30 лет устанавливался на основе официальной цены золота 35 долл. за одну тройскую унцию, которая была определена Бреттон-Вудским соглашением в 1944 г. [10].

В результате отказа от фиксированного золотого содержания денежных единиц и перехода к неполноценным деньгам вопрос о масштабе цен приобрел дискуссионный характер и до сих пор остается не решенным. Существует несколько версий решения данной проблемы. Согласно одним утверждениям неполноценные деньги выступают представителями золота, а изменение их массы в обращении в ту или иную сторону свидетельствует о соответствующем изменении массы золота, которое они представляют. Согласно другой версии, масштаб цен основан на традиционных соотношениях, которые существовали при обращении полноценных денег. Однако масштаб цен, принятый на территории государства, действителен только в пределах его границ. Соответственно при переходе от одной национальной валюты к другой происходит переход от одного масштаба цен к другому. Согласно третьей версии в основе масштаба цен лежит уровень прожиточного минимума на одного человека, т. е. затраты труда на производство товаров сопоставляются с затратами на воспроизводство рабочей силы. Здесь мы хотели бы подчеркнуть определенную логическую совместимость двух последних версий. Если валютные курсы отражают соотношение масштабов цен различных национальных валют, то отрицать при этом взаимосвязь между уровнем жизни населения страны и степенью устойчивости ее валюты сложно даже с позиции простого обывателя.

Стоимость рабочей силы как товара, лежащего в основе масштаба цен знаков стоимости, на наш взгляд, имеет сегодня не меньшее значение, чем золото, выступавшее в качестве масштаба цен в эпоху обращения полноценных денег. В пользу этой версии хотелось бы привести следующие аргументы. Во-первых, любые экономические отношения, в том числе денежные, возникают по инициативе людей для удовлетворения их самых разнообразных потребностей, а не наоборот. Во-вторых, рабочая сила как особый товар, в отличие от любого другого вида товара (даже золота), играющий в экономике двоякую роль. Первая формулируется одним из положений трудовой теории стоимости: в основе меновой стоимости товаров лежат затраты общественно необходимого труда на их производство. Здесь рабочая сила выступает в качестве одного из факторов производства, цена которого определяется уровнем заработной платы. Вторая находит свое отражение в одном из ключевых положений теории предельной полезности: стоимость (или ценность) блага определяется человеком по величине конечной (предельной) полезности блага в процессе его потребления. Здесь рабочая сила выступает уже в качестве потребителя созданных при ее непосредственном участии материальных и нематериальных благ. Стоимость рабочей силы теперь определяется общественными затратами на ее воспроизводство или уровнем прожиточного минимума.

Критики такого подхода к определению масштаба цен согласны с тем, что он приемлем только по отношению к потребительским товарам, но не к товарам производст- 
венного назначения. Однако следует заметить, что товары производственного назначения можно рассматривать как промежуточную продукцию, стоимость которой будет включена в состав основных средств, задействованных в производстве потребительских товаров, и соответственно отразится в составе себестоимости последних.

Существуюшая взаимосвязь между покупательной способностью денег и уровнем заработной платы является также объектом изучения в рамках теории инфляции. Теория инфляции приводит дополнительную аргументацию взаимообусловленности заработной платы, с одной стороны, и инфляции спроса и инфляции издержек, с другой. Если повышение уровня заработной платы не сопровождается адекватно необходимым ростом производительности труда, то складывается ситуация, когда темп увеличения платежеспособного спроса опережает темп роста предложения, что приводит к росту цен. Кроме того, если рост заработной платы не сопровождается изменением структуры затрат таким образом, чтобы полная себестоимость оставалась бы на прежнем уровне, то для сохранения прежней доли прибыли в цене также потребуется рост последней. Если же рост цен вызван причинами, не связанными с повышением заработной платы, то рано или поздно (в зависимости от темпов роста цен и характера проводимой социаль- ной политики) это спровоцирует увеличение заработной платы, которая вновь потянет за собой цены. Таким образом, круг замыкается: увеличение заработной платы подталкивает рост цен, а рост цен провоцирует повышение заработной платы [11].

А.М. Косой дает научное обоснование тому, что с тех пор, как было прекращено установление официального золотого содержания знаков стоимости, минимальный размер оплаты труда можно рассматривать в качестве масштаба цен современных денег. Роль экономической основы масштаба цен может выполнить товар, минимальная цена которого официально устанавливается законом государства. Таким единственным товаром является рабочая сила.

Когда юридическим законом Российской Федерации устанавливается минимальный размер оплаты труда, то тем самым косвенно устанавливается содержащееся в рубле минимальное время, в течение которого благодаря рублю в определенной мере материально обеспечивается воспроизводство рабочей силы. Следовательно, рубль содержит частицу стоимости, выраженную во времени. Поскольку эта частица стоимости косвенно определяется законом Российской Федерации, она становится экономической основой, эталоном, масштабом цен на рабочую силу, а следовательно, масштабом цен всех товаров, производимых благодаря труду [6].

Таблица 2

Реальная среднемесячная начисленная заработная плата работников по субъектам Российской Федерации за 2010-2013 гг.

\begin{tabular}{|l|c|c|c|c|}
\hline \multirow{2}{*}{\multicolumn{1}{|c|}{ Федеральный округ }} & \multicolumn{4}{|c|}{ Заработная плата, \% к предыдущему году } \\
\cline { 2 - 5 } & 2010 & 2011 & 2012 & 2013 \\
\hline Российская Федерация & 105,2 & 102,8 & 108,4 & 104,8 \\
\hline Центральный & 105,8 & 103,4 & 107,4 & 104,3 \\
Северо-Западный & 105,4 & 101,1 & 107,6 & 105,0 \\
Южный & 103,3 & 101,9 & 109,4 & 106,3 \\
Северо-Кавказский & 101,6 & 101,4 & 115,0 & 108,8 \\
Приволжский & 104,5 & 103,3 & 108,8 & 105,2 \\
Уральский & 104,7 & 102,8 & 107,5 & 103,2 \\
Сибирский & 105,8 & 103,6 & 108,2 & 103,9 \\
Дальневосточный & 104,5 & 105,4 & 108,8 & 105,0 \\
\hline
\end{tabular}


Рассматривая различные темпы роста эффективной заработной платы (отношения заработной платы к производительности труда) Элвин Хансен отмечает следующие моменты. При умеренном росте эффективной заработной платы происходит ползучая, но упорная инфляция заработной платы. Но слишком быстрый рост приведет к серьезным нарушениям в заработной плате и распределении доходов в пользу групп, находящихся в наиболее выгодных стратегических позициях. Неравенство может быть очень опасно для поддержания стабильности и социального единения демократического общества. Следовательно, стабильность эффективной заработной платы и соответственно уровня цен и стоимости денег требует постоянной заботы для сохранения и жизнеспособности свободного общества [14].

3. Опыт европейских стран по согласованию денежно-кредитной и бюджетной политик государств. Особо интересным и полезным для России нам представляется опыт Немецкого Федерального банка в части реализации денежно-кредитной политики в период, предшествовавший введению единой европейской валюты. Здесь стоит напомнить, что немецкая марка в то время признавалась одной из самых стабильных валют не только в Западной Европе, но и в мире, а большинство принципов функционирования Немецкого Федерального банка легли в основу деятельности Европейской системы центральных банков.

С позиций учета региональных особенностей при разработке и реализации единой государственной денежно-кредитной политики возникает необходимость считаться с социально-экономическими интересами отдельных субъектов федерации. Так, в соответствии с Законом о Немецком Федеральном банке, в редакции от 22.10.1992 г., в объединенной Германии функционировало девять центральных банков земель, при каждом из которых существовал совет, который обсуждал с председателем Центрального банка земли вопросы денежной и кредитной политики в рамках соответствующего региона. Особого внимания заслуживает состав этих

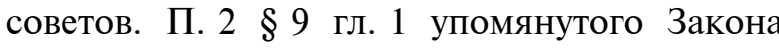
гласил, что совет состоит из 14 членов, вла- деющих особыми знаниями в области кредитной системы. Половина членов должны выбираться из различных отраслей кредитного дела, остальные - из коммерческого хозяйства, торговли, системы страхования, свободных профессий, сельского хозяйства, а также из рядов рабочих и служащих [9]. Таким образом, в ходе разработки и реализации денежно-кредитной политики каждой земли не могли не учитываться интересы основных отраслей экономики региона и даже отдельных социальных групп населения.

В свете наметившихся сегодня тенденций объединения и укрупнения отдельных регионов Российской Федерации неизбежно встанет вопрос об адекватных институциональных изменениях органов государственного экономического регулирования, в том числе территориальных учреждений Банка России. Возможно, в целях повышения значимости последних для дальнейшего развития региональных экономик потребуется делегирование части полномочий из центра в регионы. Особого внимания будут заслуживать также взаимоотношения территориальных учреждений Центрального Банка с региональными органами государственной власти по вопросам согласования денежно-кредитной и бюджетной политик регионов.

Наблюдающаяся дифференциация региональных цен - это лишь внешнее проявление разнонаправленных векторов развития региональных экономик, корни которого кроются в сфере производства. Денежно-кредитная политика служит инструментом регулирования, прежде всего, сферы обращения, но нельзя не принимать во внимание ее косвенное влияние и на сферу производств.

Здесь заслуживает внимания опыт Европейского Сообщества по разработке критериев конвергенции, соответствие которым позволяло европейским странам вступить в третий этап Экономического и Валютного Союза и ввести единую валюту [12]. Некоторые из них могли бы в той или иной мере применяться в Российской Федерации. Кратко остановимся на наиболее в этом случае приемлемых.

Первым критерием является достижение высокой степени ценовой стабильности. Она оценивалась по среднему уровню инфляции соответствующего государства-члена 
ЕС за последние 12 месяцев, который сравнивался с показателями трех государствчленов ЕС, имевших самые низкие уровни инфляции (по данным 1996 г. это 3-3,5 в год). Вторым критерием является ограничение чрезмерного бюджетного дефицита. Ограничение устанавливалось в процентах от ВВП страны. Третьим критерием является соблюдение долгосрочных процентных ставок на определенном уровне, который складывался в тех же трех государствах-членах ЕС, где фиксировался минимальный уровень инфляции. Остальные критерии в большей степени касались колебаний валютных курсов, которые в плоскости рассматриваемых нами проблем не представляют интереса. Вместе с тем само появление практики разработки и реализации денежно-кредитной политики, учитывающей особенности отдельных регионов страны, может подсказать другие критерии оценки и целевые параметры регулирования.

Результаты исследования и выводы. Таким образом, в условиях региональной дифференциации уровня цен и покупательной способности российского рубля выйти на новый уровень гармонизации денежно-кредитной и бюджетной политик можно, по нашему мнению, за счет как институциональных преобразований, так и внедрения целевых ориентиров, направленных на выравнивание уровней социально-экономического развития регионов России.

В части институциональных преобразований в целях повышения значимости территориальных учреждений Банка России для дальнейшего развития региональных экономик предлагается делегирование им части полномочий из центра. Особого внимания будут заслуживать также взаимоотношения территориальных учреждений Центрального Банка с региональными органами государственной власти по вопросам согласования денежно-кредитной и бюджетной политики регионов. Подобная практика могла бы сочетаться с деятельностью в регионе специального совещательного органа, в состав которого входили бы представители не только денежных и финансовых властей региона, но и различных отраслей экономики и социальных групп населения.
В качестве целевых ориентиров развития экономики регионов можно принять первоначально видоизмененные Маастрихтские критерии конвергенции ЕС. Мы предлагаем использовать для начала следующие ориентиры.

1. Ориентир по дефициту и долгам регионального бюджета. Региональный бюджет должен сводиться с профицитом или нулевым сальдо. В исключительных случаях допускается дефицит регионального бюджета, который не должен превышать $3 \%$ от валового регионального продукта (ВРП) к концу финансового года. Региональный долг не должен превышать $60 \%$ от ВРП на конец финансового года или уверенно приближаться к этому уровню.

2. Ориентир по стабильности цен. Индекс потребительских цен в регионе не должен превышать более чем на $1,5 \%$ средний уровень в трех-пяти субъектах РФ, достигших наилучших результатов в сфере стабильности цен (т. е. имеющих минимальные показатели инфляции).

3. Ориентир по процентным ставкам по региональным займам. Долгосрочная процентная ставка по региональным займам сроком на 10 лет не должна превышать более чем на $2 \%$ средний уровень данной ставки в трех-пяти субъектах РФ, достигших наилучших результатов в сфере стабильности цен.

Нынешние проблемы стран зоны евро не могут, по нашему мнению, дискредитировать эффективность критериев конвергенции, на которые мы здесь опираемся, поскольку предусмотренные изначально экономические рычаги воздействия за их нарушение были нивелированы в итоге политическими решениями.

Предлагаемые нами ориентиры требуют дополнительной апробации как на ретроспективных данных, так и с учетом меняющихся экономических условий, характера межбюджетных отношений и источников поступления доходов в региональные бюджеты.

В этой связи наши дальнейшие исследования будут направлены на дальнейшее уточнение корреляционных связей между показателями денежно-кредитной и бюджетной политики на региональном уровне, на определение внутри каждого федерального округа наиболее успешных субъектов РФ по совокупно- 
сти таких критериев, как показатели ВРП, индекса потребительских цен, реальной среднемесячной начисленной заработной платы, уровня процентных ставок, объемам кредитных вложений, освоения новых инвестиционных проектов и др. На основе полученных результатов предполагается выработка критериев установления пороговых значений целевых ориентиров и условий их возможного пересмотра. Не исключена также разработка других целевых ориентиров, заменяющих или дополняющих исходные.

\section{СПИСОК ЛИТЕРАТУРЫ}

1. Бабкин А.В. О соотношении понятий «экономическая безопасность» и «экономический потенциал» // Научно-технические ведомости Санкт-Петербургского государственного политехнического университета. Экономические науки. 2013. № 4(175). С. 121-127.

2. Бабкин А.В. Инструментарий для оценки экономической безопасности промышленного предприятия // Экономика и промышленная политика: теория и инструментарий / под ред. А.В. Бабкина. СПб., 2014. С. 510-529.

3. Бабкин А.В., Новиков А.О. Теоретические аспекты и тенденции глобализации экономики // Глобализация экономики и развитие промышленности: теория и практики / под ред. А.В. Бабкина. СПб., 2013. С. 33-59.

4. Грачев А.В., Пузыревский Л.С., Бабкин А.В. Теневая экономика как инструмент обеспечения экономической безопасности хозяйствующих субъектов // Научно-технические ведомости Санкт-Петербургского государственного политехнического университета. Экономические науки. 2011. № 3(125). C. 214-218.

5. Демиденко Д.С., Бабкин А.В., Кудрявцева Т.Ю. Теоретические аспекты оценки эффективности бюджетных расходов // Научно-технические ведомости Санкт-Петербургского государственного политехнического университета. Экономические науки. 2009. № 3(79). С. 255-262.

6. Косой А.М. Платежный оборот: исследование и рекомендации. М.: Финансы и статистика, 2005. C. $70-71$.

7. Мараховский А.С., Бабкин А.В., Ширяева Н.В. Оптимальное управление неустойчивыми макроэкономическими системами // Научно-технические ведомости Санкт-Петербургского государст- венного политехнического университета. Экономические науки. 2015. № 2(216). С. 18-24.

8. Моисеев С.P. Денежно-кредитный энциклопедический словарь. М.: Дело и Сервис, 2006. С. 316.

9. Немецкий Федеральный банк. Денежнополитические задачи и инструменты. [Специальное издание Немецкого Федерального банка № 7. Русская редакция, идентичная № 6 немецкого издания, вышедшего в феврале 1993 г.]. 177 с.

10. Пшеничников В.В., Бичева Е.Е. Россия и Всемирная торговая организация: финансовые аспекты взаимодействия в условиях глобального экономического кризиса. LAP LAMBERT Academic Publishing, Saarbrücken, 2013. 192 c.

11. Пшеничников В.В. Инфляция как фактор неопределенности в системе стратегического финансового планирования промышленного предприятия // Научно-технические ведомости СанктПетербургского государственного политехнического университета. Экономические науки. 2013. № 6-2(185). С. 125-132.

12. Пшеничников В.В. Дискуссии о необходимости единой мировой валюты в условиях глобализации и многополярности современного мира // Научно-технические ведомости Санкт-Петербургского государственного политехнического университета. Экономические науки. 2015. № 2(216). C. 7-17.

13. Федеральная служба государственной статистики Российской Федерации. URL: http:// www.gks.ru (дата обращения: 05.05.2015).

14. Хансен Элвин. Денежная теория и финансовая политика: пер. с англ. М.: Дело, 2006. С. 193.

15. Яковец Ю.В. Глобальные экономические трансформации XXI века. М.: Экономика, 2011. $382 \mathrm{c}$.

\section{REFERENCES}

1. Babkin A.V. About a ratio of the concepts «economic safety» and «economic potential». St. Petersburg State Polytechnical University Journal. Economics, 2013, no. 4(175), pp. 121-127. (rus)

2. Babkin A.V. Instrumentarii dlia otsenki ekonomicheskoi bezopasnosti promyshlennogo predpriiatiia. Ekonomika $i$ promyshlennaia politika: teoriia $i$ instrumentarii. Pod red. A.V. Babkina. SPb., 2014. S. 510-529. (rus)

3. Babkin A.V., Novikov A.O. Teoreticheskie aspekty i tendentsii globalizatsii ekonomiki. Globalizatsiia ekonomiki $i$ razvitie promyshlennosti: teoriia i praktiki. Pod red. A.V. Babkina. SPb., 2013. S. 33-59. (rus) 
4. Grachev A.V., Puzyrevskyi L.S., Babkin A.V. Shadow economy as a tool for maintenance of economic security businesses. St. Petersburg State Polytechnical University Journal. Economics, 2011, no. 3(125), pp. 214-218. (rus)

5. Demidenko D.S., Babkin A.V., Kudryavtseva T.U. Theoretical aspects of the estimation of efficiency of budgetary expenses. St. Petersburg State Polytechnical University Journal. Economics, 2009, no. 3(79), pp. 255-262. (rus)

6. Kosoi A.M. Platezhnyi oborot: issledovanie i rekomendatsii. M.: Finansy i statistika, 2005. S. 70-71. (rus)

7. Marahovskij A.S., Babkin A.V., Shiryaeva N.V. Optimal control over unstable macroeconomic systems. St. Petersburg State Polytechnical University Journal. Economics, 2015, no. 2(216), pp. 18-24.

8. Moiseev S.R. Denezhno-kreditnyi entsiklopedicheskii slovar'. M.: Delo i Servis, 2006. S. 316. (rus)

9. Nemetskii Federal'nyi bank. Denezhnopoliticheskie zadachi i instrumenty. Spetsial'noe izdanie Nemetskogo Federal'nogo banka № 7. Russkaia redaktsiia, identichnaia № 6 nemetskogo izdaniia, vyshedshego v fevrale 1993 g. 177 s. (rus)

10. Pshenichnikov V.V., Bicheva E.E. Rossiia i Vsemirnaia torgovaia organizatsiia: finansovye aspekty vzaimodeistviia v usloviiakh global'nogo ekonomicheskogo krizisa. LAP LAMBERT Academic Publishing, Saarbrücken, 2013. $192 \mathrm{~s}$.

11. Pshenichnikov V.V. Inflation as uncertainty factor in strategic financial planning system of industrial enterprises. St. Petersburg State Polytechnical University Journal. Economics, 2013, no. 6-2(185), pp. 125-132.

12. Pshenichnikov V.V. Discussions on the need for a single world currency in today's globalised multipolar world. St. Petersburg State Polytechnical University Journal. Economics, 2015, no. 2(216), pp. 7-17.

13. Federal'naia sluzhba gosudarstvennoi statistiki Rossiiskoi Federatsii. URL: http://www.gks.ru (data obrashcheniia: 05.05.2015). (rus)

14. Khansen Elvin. Denezhnaia teoriia i finansovaia politika: per. s angl. M.: Delo, 2006. S. 193. (rus)

15. Iakovets Iu.V. Global'nye ekonomicheskie transformatsii XXI veka. M.: Ekonomika, 2011. 382 s. (rus)

ПШЕНИЧНИКОВ Владислав Владимирович - доцент кафедры «Финансы и кредит» Воронежского государственного аграрного университета имени императора Петра I, кандидат экономических наук.

394087, ул. Мичурина, д. 1, г. Воронеж, Россия. E-mail: wladwp@yandex.ru

PSHENICHNIKOV Vladislav V. - Voronezh State Agricultural University

394087. Mitchurina str. 1. Voronezh. Russia. E-mail: wladwp@yandex.ru 